\title{
Titanium-Anchored Gold on Silica for Enhanced Catalytic Activity in Aqueous Ethanol Oxidation
}

\author{
Sotiria Mostrou, Mark A. Newton, Andreas Tarcevski, Andreas Nagl, Karin Föttinger, \\ and Jeroen A. van Bokhoven*
}

Cite This: Ind. Eng. Chem. Res. 2021, 60, 1564-1575

Read Online

ABSTRACT: The heterogeneously catalyzed oxidation of bioethanol offers a promising route to bio-based acetic acid. Here, we assess an alternative method to support gold nanoparticles, which aims to improve selectivity to acetic acid through minimizing overoxidation to carbon dioxide. The most promising support system is 5 wt \% titanium on silica, which combines the high surface area of silica with the stabilizing effect of titania on the gold particles. Compared to gold-silica systems, which require a complex synthesis method, small quantities of titanium promoted the formation of gold nanoparticles during a simple depositionprecipitation. Characterization of the catalyst with $\mathrm{X}$-ray absorption spectroscopy shows that titanium is highly dispersed in the form of small, possibly dimeric, titanium(IV) structures,

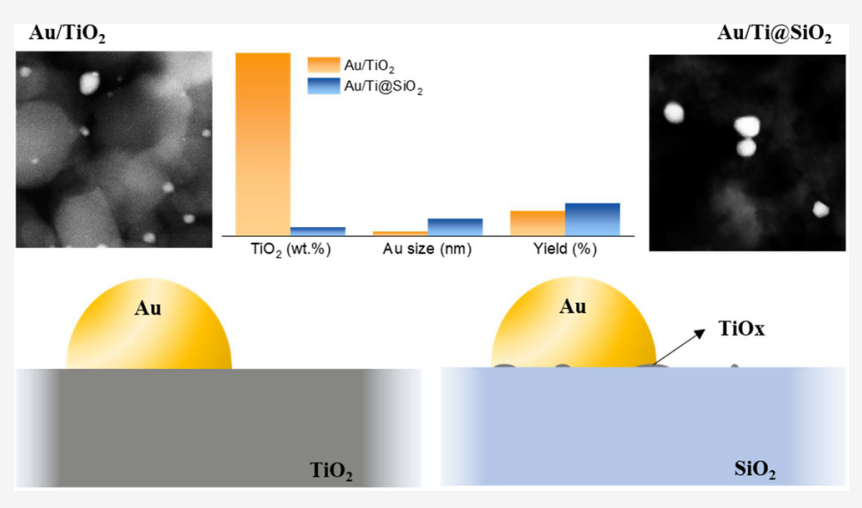
which are isolated and stabilize gold nanoparticles, possibly minimizing sintering effects during synthesis. The size of the gold particles depends on the pre-treatment of the titanium-silica support before gold deposition, with larger titanium structures hosting larger gold particles. Acetic acid yield over the titanium-silica-supported gold systems improved by about 1.6 times, compared to pure titania-supported gold. The high activity of those catalysts suggests that bulk, crystalline titania is not required for the reaction, encouraging the use of mixed supports to combine their benefits. Those support systems, besides improving selectivity, offer high surface area and a low-cost filler material, which brings ethanol oxidation one step further to the industry. Additionally, the low loading of titanium permits studying the reaction mechanisms on the gold-titanium interface with bulk characterization techniques.

\section{INTRODUCTION}

Using bio-based acetic acid in the polymer industry can significantly reduce the eco-footprint of various synthetic materials. One of the most promising routes to bio-based acetic acid is the heterogeneously catalyzed oxidation of bioethanol. ${ }^{1,2}$ A much-researched heterogeneous catalyst for the partial oxidation is gold-supported on metal oxides. Christensen et al. was the first to compare the selective oxidation of ethanol over gold, platinum, and palladium nanoparticles (NPs) in the aqueous phase. ${ }^{3}$ Since then, several gold-based systems, supported upon a variety of inorganic oxides, were tested for aqueous ethanol oxidation. ${ }^{4-8}$ The most frequently reported and best-performing is gold supported on titania, which at $433 \mathrm{~K}$ reached up to a $70 \%$ acetic acid yield. ${ }^{9}$ Despite the promising acetic acid yields, until now, the studied catalysts are still far from suitable for largescale commercial application. A typical problem encountered in heterogeneous catalysis by gold particles is the loss of activity through sintering, i.e., increase of the gold particle size, just through exposure to heat and light. ${ }^{10}$ Catalysis by gold is strongly dependent of the size of the gold particles as decidedly demonstrated in the oxidation of carbon monoxide. ${ }^{11-13}$ The second problem is the over-oxidation of the ethanol to yield carbon dioxide, which is stronger in the liquid-phase ethanol oxidation. Rational optimization of the catalyst to promote the acetic acid formation and suppress over-oxidation pathways requires a deep understanding of the surface reaction mechanism, which is, to this day, a matter of debate. The mechanisms proposed in the literature provide valuable information but are often ambiguous. Predominantly, they propose a Langmuir-Hinshelwood reaction mechanism, where ethanol adsorbs on the gold surface and sequentially reacts with atomic oxygen or hydroxide to acetic acid via the intermediate acetaldehyde. ${ }^{7,8,14}$ These propositions have, in whole or in part, relied either on theoretical calculations over ideal, flat gold surfaces that are too dissimilar to a real, active gold NP on a surface, ${ }^{8,14,15}$ or they were conducted in strongly

Received: June 12, 2020

Revised: November 25, 2020

Accepted: November 30, 2020

Published: December 9, 2020

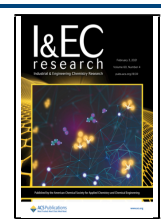


basic environments, which cannot be simply extrapolated to the ultimately desired $\mathrm{pH}$-neutral aqueous ethanol oxidation process. ${ }^{8,15}$ Moreover, they have sometimes proposed elemental steps that are energetically unfavorable, such as the dissociative adsorption of oxygen on gold and titania. ${ }^{7}$

Recent advances in the understanding of the mechanism of ethanol oxidation to acetic acid suggested that the only catalytic step is the oxidative dehydrogenation of the substrate ethanol. ${ }^{16} \mathrm{~A}$ competing reaction is the total oxidation of ethanol to carbon dioxide, following ethanol adsorption and $\mathrm{C}-\mathrm{C}$ bond cleavage. Hence, the catalyst needs to be welltuned to increase the selectivity toward the acetaldehyde, which is non-catalytically oxidized to acetic acid in the liquid phase instead of carbon dioxide. The selection and optimization of the catalyst support is one path to reduce the selectivity toward carbon dioxide. The sensitivity of the reaction to the support material is clear in the comparison of $\mathrm{Au} / \mathrm{TiO}_{2}$ and $\mathrm{Au} / \mathrm{MgAl}_{2} \mathrm{O}_{4}$, where the former performs significantly better despite the similar gold particle size., The support can influence the adsorption and activation of reactants on the surface, as well as the formation of gold particles, i.e., their shape and size. ${ }^{11,17}$ The adsorption energy between the gold and the support dictates the catalyst synthesis method, the gold size after synthesis, and the resistance to sintering during reaction conditions. The sintering resistance of the particles depends on their chemical potential; the higher the chemical potential, the higher the thermodynamic driving force to sinter. ${ }^{18}$ Here, the chemical potential depends on (i) the nature of metal, (ii) the nature of the support, (iii) the size of the metal particles, and (iv) the shape of metal particles. Therefore, a decrease in chemical potential through alteration of the support can help to stabilize metal particles on the support surface. Titania is the best support for gold catalysts until now but suffers from deactivation due to sintering under reaction conditions, and a relatively high selectivity to carbon dioxide. ${ }^{19}$ Other supports, such as ceria, zinc oxide, and alumina, behave in a similar manner to titania in that they can support small gold particles. These systems, however, do not yield any improvement in catalytic performance compared to titania. ${ }^{20}$ Theoretical studies of the adhesion energy between the metal and support underscore these observations and can offer a further guideline to selecting potential candidates. For instance, the adhesion energy of silver particles increases in the order $\mathrm{MgO} \leq \mathrm{Al}_{2} \mathrm{O}_{3}$ $\leq \mathrm{CeO}_{2} \leq \mathrm{TiO}_{2} \leq \mathrm{SiO}_{2} \leq \mathrm{Fe}_{3} \mathrm{O}_{4}{ }^{18}$ Extrapolating the above trend to other noble metals, like gold, suggests silica and $\mathrm{Fe}_{3} \mathrm{O}_{4}$ as potential alternatives to titania. The most promising is silica because of its low cost, high surface area, inertness, chemical stability, i.e., resistance to redox reactions, and mechanical stability. Gold supported on silica has shown promising activity in ethanol oxidation. ${ }^{5}$ The limitation in this system, however, lies in the ability to synthesize small gold particles. To avoid this problem, Sun et al. used gold colloids, which they immobilized on the support by adjusting the $\mathrm{pH}$ of the solution to 0.5 . ${ }^{5}$ Theoretical studies have shown that pure gold clusters adsorb only weakly on the silica surfaces via van der Waals forces. This implies that they will be mobile and will sinter rapidly under reaction conditions of the study. ${ }^{21}$ However, the addition of one or more titanium atoms on the gold cluster results in remarkably large adsorption energies between the titanium-doped gold cluster and silica. ${ }^{21}$ The latter derives from theoretical results, which suggest an alloy of gold and titanium; however, experimentally, titanium metal would readily oxidize. Still, titania, which strongly bonds gold particles and titanium oxide on silica, could offer a similarly high catalytic activity as gold supported on bulk titania. Here, we aim to combine the physical properties of silica, notably its high surface area, with the chemical properties of titania to synthesize mixed-supported gold catalysts for selective ethanol oxidation. We synthesized highly dispersed titanium(IV) on silica by wet impregnation, which we then treated at different temperatures to understand the effect of the titanium structure on the gold particle formation. We thoroughly characterized the structure of titanium on silica with electron microscopy, Xray diffraction, and $\mathrm{X}$-ray absorption spectroscopy. Already, the presence of low loading of titanium ( 5 wt \%) allowed the formation of small and stable gold particles on the mixed-oxide support. The systems showed similar catalytic activity as the bulk-titania-supported gold catalysts and a slightly higher selectivity to acetic acid. The similarities between the activity of the titanium-silica and bulk titania support show that the properties of bulk titania are not the key factor in the catalytic oxidation of ethanol. As an additional advantage, the titaniumsilica supported gold is better adapted for studying the goldtitanium interaction with bulk characterization techniques.

\section{EXPERIMENTAL SECTION}

Catalysts Synthesis. A 1 wt $\% \mathrm{Au} / \mathrm{TiO}_{2}$ (AUROlite, Strem, Lot: 26622800) commercial catalyst was used as the benchmark catalyst, as received, unless otherwise specified. To minimize the potential for alterations to this benchmark, the catalyst was stored at about $250 \mathrm{~K}$. Transmission electron microscopy analysis of the fresh and stored catalyst is presented in the Supporting Information.

$\mathrm{Ti} @ \mathrm{SiO}_{2}$ supports (5 wt \%) were made by wet impregnation of fumed silica (99.9\%, Alfa Aesar). Before use, silica was dispersed in small amounts of isopropanol, to form an agglomerated paste, which was dried at around $300 \mathrm{~K}$ in a vacuum. The dried silica was crushed into powder. This process transformed the high void, feathery-like fumed silica into a practicable aggregated powder without altering the chemical and physical properties of the support. A total of 1.00 $\pm 0.002 \mathrm{~g}$ of the silica support was introduced into a flask containing $100 \pm 0.5 \mathrm{~mL}$ of isopropanol (99\%, Sigma Aldrich). A total of $0.19 \pm 0.005 \mathrm{~g}$ titanium(IV) isopropoxide (99.999\%, Aldrich-Fine chemicals) was added to the mixture. The slurry was stirred at $800 \mathrm{rpm}$ at room temperature. After $3 \mathrm{~h}$, the solid was separated by vacuum filtration and washed with isopropanol. The collected paste was dried at $333 \mathrm{~K}$ under an air atmosphere. The dried support was used as is $\left(\mathrm{Ti} @ \mathrm{SiO}_{2}\right)$ or calcined in static air at $473\left(\mathrm{Ti} @ S i O_{2}-200\right)$ and $1173 \mathrm{~K}$ ( $\left.\mathrm{Ti} @ \mathrm{SiO}_{2}-900\right)$ for $4 \mathrm{~h}(5 \mathrm{~K} / \mathrm{min})$.

Gold was deposited using a deposition precipitation method adapted from Zanella et al. ${ }^{22}$ The gold precursor solution was made by dissolving $60 \pm 0.09 \mathrm{mg}$ hydrogen tetrachloroaurate(III) trihydrate (99.99\%, ABCR), equivalent of $1.5 \mathrm{wt} \% \mathrm{Au}$, $5.0 \pm 0.003 \mathrm{~g}$ urea $(\geq 99.5 \%$, Fluka), and $42 \pm 0.05 \mathrm{mg}$ magnesium citrate dibasic (99.999\%, Roth) in $100 \pm 0.5 \mathrm{~mL}$ distilled water. The solution was transferred into a $250 \mathrm{~mL}$ round-bottom flask where $2.0 \pm 0.003 \mathrm{~g}$ of the support was added. The slurry was stirred at $800 \mathrm{rpm}$ and heated to $353 \mathrm{~K}$. After $4 \mathrm{~h}$, the heating was stopped, and the mixture was cooled by an ice bath. The solid was separated by vacuum filtration and was washed with distilled water at least three times to remove the excess chlorine. The collected paste was dried at 
$323 \mathrm{~K}$ under vacuum for at least $48 \mathrm{~h}$. Finally, the dried powder was calcined in static air at $473 \mathrm{~K}(5 \mathrm{~K} / \mathrm{min})$ for $4 \mathrm{~h}$.

Characterization. X-ray diffraction (XRD) patterns were acquired on a PANalytical X'Pert PRO-MPD diffractometer, operating with $\mathrm{Cu} \mathrm{K} \alpha$ radiation. Data were recorded in the $10-70^{\circ} 2 \theta$ range with an angular step size of $0.050^{\circ}$ and a counting time of $2 \mathrm{~s}$ per step. The crystal size was evaluated by fitting the Bragg reflections to Gaussian and Lorentzian functions using TOPAS $6 .^{23}$ The full width at half-maximum (FWHM) was deconvoluted from these fittings, and the crystallite size was calculated by using the Scherrer equation. ${ }^{24}$

Scanning transmission electron microscopy (STEM) investigations were performed on an aberration-corrected STEM microscope HD-2700CS (Hitachi). ${ }^{25}$ The microscope was operated at an acceleration potential of $200 \mathrm{kV}$ (cold field emitter). In the high-angle annular dark-field STEM (HAADFSTEM), the image is generated with incoherently scattered electrons, resulting in an intensity that is a strong function of the atomic number strongly increasing with the atomic number (Z-contrast). The images were recorded with frame times between 20 and $40 \mathrm{~s}$. Further, analytical investigation was achieved with an energy-dispersive X-ray spectrometer (EDX) attached to the microscope column.

The specific surface area $\left(S_{\mathrm{BET}}\right)$ of the as-prepared materials was measured by nitrogen physisorption at $77 \mathrm{~K}$ in a Micromeritics TriStar unit and determined by the BET method. Before measurement, the samples were degassed at $423 \mathrm{~K}$ in vacuum for $2 \mathrm{~h}$.

The Ti K edge X-ray absorption spectroscopic measurements were performed at the I20-scanning beamline at the Diamond Light Source (DLS) in Oxfordshire, United Kingdom. All measurements were made in fluorescence mode unless otherwise stated. The measurements were performed with a $\mathrm{Si}(111)$ double crystal monochromator under constant flux $\left(10^{12} \mathrm{ph} / \mathrm{s}\right)$. Each scan required about 20 min, which recorded at the Ti $\mathrm{K}$ edge $(4.9664 \mathrm{keV})$ in partial fluorescence yield mode using a five-element silicon drift detector. The recorded spectra were calibrated using gold or titanium foils. The spectra were normalized, analyzed, and merged (at least three scans) using Athena XAS Data Processing 0.9.26. ${ }^{26}$

Ti K edge EXAFS data was redacted and normalized using the Athena XAS Data Processing package (version 0.9.26). ${ }^{26}$ The $R$-factor was calculated as follows: ${ }^{27}$

$$
R \%=\sum_{i}^{N} 1 / \sigma_{i}\left(X_{i}^{e}(k)-X_{i}^{t}(k)\right)^{2} \times 100 \%
$$

where $X_{i}^{e}$ and $X_{\mathrm{i}}^{\mathrm{t}}$ are the experimental and theoretical EXAFS, respectively, and $k$ is the photoelectron wave vector $(\AA-1) . \sigma_{i}$ is the uncertainty in the data, with

$$
1 / \sigma_{i}=k_{i}^{n} / \sum_{j}^{N} k_{i}^{n}\left(X_{i}^{e}\left(k_{j}\right)\right)^{2}
$$

The reduced $\mathrm{chi}^{2}$ function $\left(\times 10^{-6}\right)$ was calculated as follows:

$$
1 /\left(N_{\text {ind }}-p\right)\left(N_{\text {ind }} / N\right) \sum_{\text {ind }} w_{i}\left(X_{i}^{e}(k)-\operatorname{chi}_{i}^{t}(k)\right)^{2}
$$

where $N_{\text {ind }}$ is the number of independent data points and $p$ is the number of parameters. ${ }^{28}$ The number maximum of independent parameters was calculated based on the Nyquist theorem:

$$
N_{\text {ind }}=(2 \times d R d K) / \pi
$$

Catalytic Testing. The catalytic testing experiments were performed in a custom-made trickle-flow reactor (Supporting Information). Oxygen (PanGas, 99.999\%) was supplied from a mass flow controller by Bronkhorst, calibrated for oxygen flow at 20 bar. The liquid flow ( $5 \pm 0.3$ wt \% ethanol solution (Fluka, >99.8\%)) was introduced with a KNAUER AZURA P 4.1S high-pressure liquid chromatography pump, equipped with a titanium $10 \mathrm{~mL}$ pump head. Before entering the reactor, the reactant stream was preheated at about $393 \mathrm{~K}$. The catalyst bed $(150 \pm 0.1 \mathrm{mg}$ catalyst diluted $1: 1$ with $\mathrm{SiC})$ was fixed with quartz wool inside a $4 \mathrm{~mm}$ inner diameter stainless steel tube (reactor); The bed was stabilized in the middle of the heating zone by a hollow stainless-steel rod of $\sim 1.5 \mathrm{~mm}$ outer diameter, which ensured a constant height and minimum back pressure (maximum 0.2 bar). An Equilibar U3L Series precision back-pressure regulator, equipped with a PTFE glass laminated diaphragm, maintained the pressure of the system. The back-pressure regulator was controlled by a Bronkhorst process pressure controller EL-PRESS P-802CV. The flows, temperature of the heater, and the pressure of the back-pressure regulator were all recorded and controlled via a custom-made LabVIEW program. The temperature of the catalyst bed was recorded on-line with a K-type thermocouple. The system pressure was also recorded before the reactor with a Keller Digital Manometer dV-2 PS. The product stream was cooled down below $280 \mathrm{~K}$ by a dry ice-water bath or a cooling coil. The liquid sample was collected in $2 \mathrm{~mL}$ chromatography vials and sealed. The catalytic testing was performed as summarized in Table 1 unless otherwise specified. The reaction conditions were chosen based on our previous study of the flow system. ${ }^{19}$

\section{Table 1. Reaction Conditions of Catalytic Testing ${ }^{a}$}

\begin{tabular}{lc}
\multicolumn{1}{c}{ condition } & \multicolumn{1}{c}{ value } \\
initial pressure (bar) & $17 \pm 1.0$ \\
reaction pressure & $17 \pm 1.0$ \\
temperature $(\mathrm{K})$ & $423 \pm 3$ \\
catalyst mass $(\mathrm{mg})$ & $150 \pm 2$ \\
catalyst:dilution ratio & $1: 1$ \\
ethanol concentration (wt \%) & $5 \pm 0.3$ \\
oxygen purity (vol.\%) & 100 \\
liquid flow $(\mathrm{mL} / \mathrm{min})$ & 0.3 \\
gas flow $(\mathrm{mL} / \mathrm{min})$ & 5 \\
residence time $(\mathrm{min})$ & 5.5 \\
product cooling (K) & $288 \pm 2$ \\
${ }^{a}$ Conditions are kept constant unless otherwise specified. \\
\hline
\end{tabular}

The liquid products were analyzed with an Agilent 7890A gas chromatography system, equipped with a flame ionization detector (FID). A total of $0.5 \mu \mathrm{L}$ of the liquid sample was injected at $343 \mathrm{~K}$ and carried in a $2 \mathrm{~mL} / \mathrm{min}$ helium flow through a DB-WAX column. The temperature of the column was constant at $313 \mathrm{~K}$ for $2 \mathrm{~min}$ and was then heated at $8 \mathrm{~K} /$ min up to $409 \mathrm{~K}$. The FID was fed by $30 \mathrm{~mL} / \mathrm{min}$ hydrogen mixed in $400 \mathrm{~mL} / \mathrm{min}$ air at $573 \mathrm{~K}$. The signal of each compound was calibrated, and the calibration line used for quantification was determined by linear regression. 
The quantification of the compounds was used to determine the ethanol conversion (X, eq 5$)$, the product selectivity $\left(S_{i}\right.$, eqs 6-9), and acetic acid yield $\left(Y_{\mathrm{AcOH}}\right.$, eq 10$)$ where EtOH is ethanol, $\mathrm{AcOH}$ is acetic acid, $\mathrm{MeCHO}$ is acetaldehyde, and EtOAc is ethyl acetate.

$$
\begin{aligned}
& X(\%)=\frac{\mathrm{EtOH}_{\mathrm{in}}(\mathrm{mol} / 1)-\mathrm{EtOH}_{\text {out }}(\mathrm{mol} / 1)}{\mathrm{EtOH}_{\mathrm{in}}(\mathrm{mol} / 1)} \times 100 \% \\
& S_{\mathrm{AcOH}}(\%)=\frac{\mathrm{AcOH}_{\text {out }}(\mathrm{mol} / 1)}{\mathrm{EtOH}_{\text {in }}(\mathrm{mol} / 1)-\mathrm{EtOH}_{\text {out }}(\mathrm{mol} / 1)} \times 100 \% \\
& S_{\mathrm{MeCHO}}(\%)=\frac{\mathrm{MeCHO}_{\text {out }}(\mathrm{mol} / 1)}{\mathrm{EtOH}_{\mathrm{in}}(\mathrm{mol} / 1)-\mathrm{EtOH}_{\text {out }}(\mathrm{mol} / 1)} \\
& \times 100 \% \\
& S_{\mathrm{EtOAc}}(\%)=2 \times \frac{\mathrm{EtOAc}_{\text {out }}(\mathrm{mol} / 1)}{\mathrm{EtOH}_{\mathrm{in}}(\mathrm{mol} / 1)-\mathrm{EtOH}_{\text {out }}(\mathrm{mol} / 1)} \\
& \times 100 \% \\
& S_{\mathrm{CO}_{2}}(\%)=100 \%-S_{\mathrm{AcOH}}-S_{\mathrm{MeCHO}}-S_{\mathrm{EtOAc}} \\
& Y_{\mathrm{AcOH}}(\%)=\frac{\mathrm{AcOH}_{\text {out }}(\mathrm{mol} / \mathrm{l})}{\mathrm{EtOH}_{\mathrm{in}}(\mathrm{mol} / 1)} \times 100 \% \\
& =\frac{S_{\mathrm{AcOH}}(\%) \times X(\%)}{100}
\end{aligned}
$$

The selectivity toward carbon dioxide was obtained from the carbon balance (eq 9) because it is the only expected gaseous product and the only gaseous carbon-containing product, ${ }^{4}$ which has also been qualitatively confirmed in our system. ${ }^{19}$

\section{RESULTS}

Catalytic Tests. We tested gold supported on titaniumsilica catalysts in the liquid-phase oxidation of ethanol, under conditions in flow. ${ }^{16}$ Figure 1 shows the ethanol conversion (top) and acetic acid yield (bottom) of the catalysts as a function of reaction temperature. The effect on other parameters has been studied in detail over gold-titania systems in a previous work; ${ }^{19} \mathrm{Au} / \mathrm{Ti} @ \mathrm{SiO}_{2}$ catalysts appear to follow similar trends, e.g., a zero-order reaction in oxygen (Supporting Information).

We also tested the commercial $\mathrm{Au} / \mathrm{TiO}_{2}$ AUROlite, as one of the best-performing systems reported for this reaction, to be used as a benchmark for comparison of our catalysts with previous works. $6,7,9,16,19 \mathrm{Au} / \mathrm{TiO}_{2}$ (orange open symbols) converts ethanol at about $373 \mathrm{~K}$ to a $15 \%$ level. At $463 \mathrm{~K}$, this has reached about 42\%. Au/ Ti@SiO 2 (red solid symbols) exhibits comparable conversion to $\mathrm{Au} / \mathrm{TiO}_{2}$, with a maximum of conversion of $40 \%$ at $453 \mathrm{~K}$. Au/ $\mathrm{Ti} @ \mathrm{SiO}_{2}-200$ (blue-dotted symbol) shows conversion that starts from about $20 \%$ at $393 \mathrm{~K}$ that doubled at $453 \mathrm{~K}$, which is the same as the benchmark. $\mathrm{Au} / \mathrm{Ti} @ \mathrm{SiO}_{2}-900$ (green times symbol) displays the same conversion as the benchmark $\mathrm{Au} / \mathrm{TiO}_{2}$ catalyst at a low temperature but is subsequently less effective at higher temperatures, reaching a maximum of $34 \%$ at $453 \mathrm{~K}$. The catalyst $\mathrm{Au} / \mathrm{SiO}_{2}$ (grey plus symbols), which does not contain titanium, shows very low activity with a maximum, and largely temperature independent, conversion of $12 \%$, lower than that of the support $\mathrm{Ti} @ \mathrm{SiO}_{2}$ (Supporting Information). The

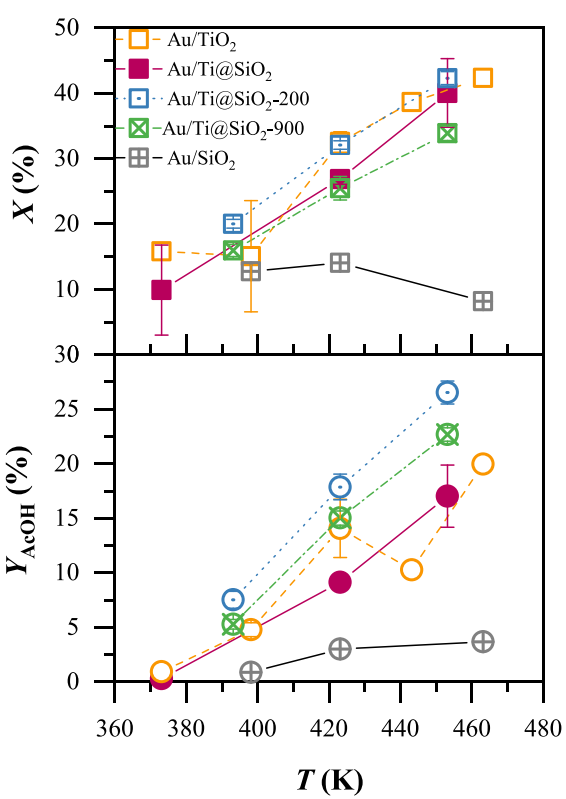

Figure 1. Ethanol conversion $(X)$ and acetic acid yield $(Y)$ of $\mathrm{Au} /$ $\mathrm{TiO}_{2}, \mathrm{Au} / \mathrm{SiO}_{2}$, and $\mathrm{Au} / \mathrm{Ti} @ \mathrm{SiO}_{2}$-based catalysts over temperature. Reaction conditions: $18 \mathrm{bar}, 5 \mathrm{~mL} / \mathrm{min} \mathrm{O}_{2}, 0.3 \mathrm{~mL} / \mathrm{min} 5$ wt $\%$ $\mathrm{EtOH} / \mathrm{H}_{2} \mathrm{O}, 0.15 \mathrm{~g}$ catalyst, $1: 1 \mathrm{SiC}$ dilution. The catalyst mass normalized conversion is available in the Supporting Information.

stability of the catalysts was asserted by evaluating the conversion at each temperature before and after exposure above $460 \mathrm{~K}$, where no significant changes were observed (Supporting Information).

However, although the conversions of the Au/ $\mathrm{Ti} @ \mathrm{SiO}_{2}-$ containing samples are similar to those of the benchmark $\mathrm{Au} /$ $\mathrm{TiO}_{2}$, these catalysts are significantly more selective to acetic acid, resulting in improved yields (Figure 1 bottom).Au/Ti@ $\mathrm{SiO}_{2}$ exhibited yields that started from 0 and reach up to a maximum $20 \%$ at $463 \mathrm{~K}$. The best-performing catalyst was the $\mathrm{Au} / \mathrm{Ti} @ \mathrm{SiO}_{2}-200$, with yields reaching to $26.4 \%$ at $453 \mathrm{~K}$, an improvement from $\mathrm{Au} / \mathrm{TiO}_{2}$ of about 1.3 times. $\mathrm{Au} / \mathrm{Ti} @ \mathrm{SiO}_{2}-$ 900 is also slightly more selective than the benchmark $\mathrm{Au} /$ $\mathrm{TiO}_{2}$. The acetic acid yield starts at $5.3 \%$ at $393 \mathrm{~K}$ and reaches up to $22.6 \%$ at $453 \mathrm{~K}$. Finally, the $\mathrm{Au} / \mathrm{Ti} @ \mathrm{SiO}_{2}$ shows a very similar yield to acetic acid, almost identical to that of $\mathrm{Au} / \mathrm{TiO}_{2}$. $\mathrm{Au} / \mathrm{SiO}_{2}$ did not exhibit high yield to acetic acid, due to the low conversion levels, despite the presence of some small NPs.

Characterization. The benchmark $\mathrm{Au} / \mathrm{TiO}_{2}$ contained 1 wt \% gold by the manufacturer. The $\mathrm{Au} / \mathrm{Ti} @ \mathrm{SiO}_{2}$ catalysts were synthesized with a theoretical loading of about $1.5 \mathrm{wt} \%$, and due to common losses of gold during such synthesis, we expect a loading of between 1 to $1.2 \mathrm{wt} \%{ }^{22}$

Figure 2a shows the XRD patterns of the silica-containing catalysts. The patterns of the $\mathrm{Ti} @ \mathrm{SiO}_{2}$ supports exhibit no crystallinity (Supporting Information). We presented the XRD patterns of $\mathrm{Au} / \mathrm{TiO}_{2}$ in a previous publication. ${ }^{19}$ All silicacontaining samples exhibit a broad peak at about $23^{\circ} 2 \theta$, typical of amorphous silica. ${ }^{29}$ The only visible reflections are at about $38.4,44.6$, and $64.8^{\circ} 2 \theta$, which correspond to metallic gold (gold reference in blue). The supports that underwent thermal treatment, i.e., Au/Ti@SiO $2-200$ and $\mathrm{Au} / \mathrm{Ti} @ \mathrm{SiO}_{2}-$ 900 , exhibit a small peak at about $35^{\circ} 2 \theta$, which corresponds to the typically second-most intense peak of rutile at $36^{\circ} 2 \theta$, shifted by $1^{\circ}$. The low intensity of that peak and the absence of 
(a) XRD patterns

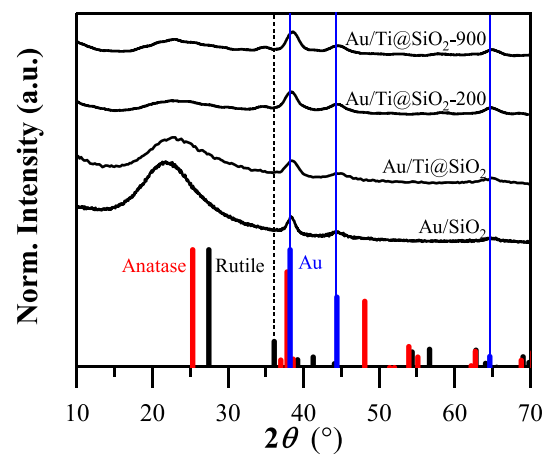

(b) Gold crystal size

\begin{tabular}{lcc}
\hline & \multicolumn{2}{c}{ Gold crystal size (nm) } \\
Catalyst & Gaussian fit & Lorentzian fit \\
\hline $\mathrm{Au} / \mathrm{SiO}_{2}$ & 6.9 & 7.2 \\
$\mathrm{Au} / \mathrm{Ti} @ \mathrm{SiO}_{2}$ & 4.7 & 4.7 \\
$\mathrm{Au} / \mathrm{Ti} @ \mathrm{SiO}_{2}-200$ & 5.4 & 5.4 \\
$\mathrm{Au} / \mathrm{Ti} @ \mathrm{SiO}_{2}-900$ & 5.6 & 5.5 \\
\hline
\end{tabular}

Figure 2. (a) XRD patterns of the fresh $\mathrm{Au} / \mathrm{SiO}_{2}$ and $\mathrm{Au} / \mathrm{Ti} @ \mathrm{SiO}_{2}$-based catalysts. The provided references are titania rutile (ICSD: 16636), anatase (ICSD: 9852), and metallic gold (ICSD: 52700). (b) Crystallite size of gold, calculated using the Scherrer equation on the XRD patterns. The Bragg reflections at $\sim 38.4,44.6$, and $64.8^{\circ} 2 \theta$ were fitted to Gaussian and Lorentzian functions using TOPAS 6 .

any other peaks, a characteristic of rutile, suggest the absence of a large fraction of crystalline titania in the samples.

We assessed the crystal size of gold in the samples from the visible reflections at $38.4,44.6$, and $64.8^{\circ} 2 \theta$ using the Scherrer equation (Figure $2 \mathrm{~b}$ ). $\mathrm{Au} / \mathrm{SiO}_{2}$ shows the largest gold crystal size, with 6.9 and $7.2 \mathrm{~nm}$ for two fits, Gaussian and Lorentzian, respectively.Au/Ti@SiO 2 has the smallest gold crystal size, 4.7 $\mathrm{nm}$, confirmed by both fits. The catalysts containing calcined supports, Au/Ti@SiO -200 and Au/Ti@SiO -900 , have both about a $5.5 \mathrm{~nm}$ crystal size. Overall, silica impregnated with titanium allows for the formation of smaller gold crystals.

Figure 3 shows transmission electron microscopy images of the gold supported on titania and silica, before (left) and after catalytic testing (right). The bright spots correspond to gold, and result from the considerable difference in atomic number between gold, titanium, and silicon, identified by energy-

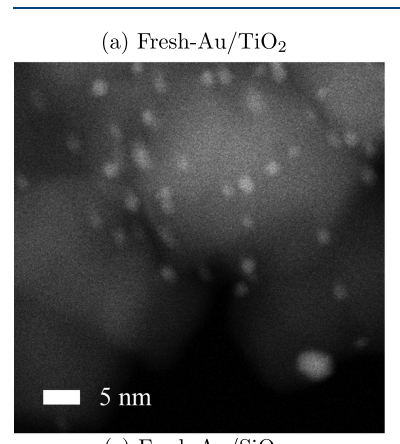

(c) Fresh- $\mathrm{Au} / \mathrm{SiO}_{2}$

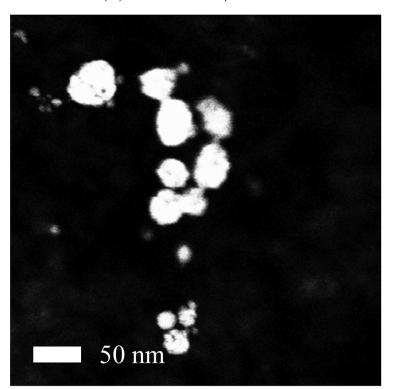

(b) Used-Au/ $\mathrm{TiO}_{2}$

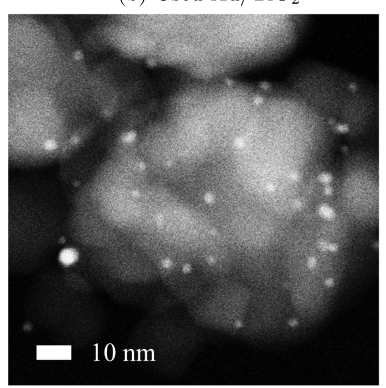

(d) Used- $\mathrm{Au} / \mathrm{SiO}_{2}$

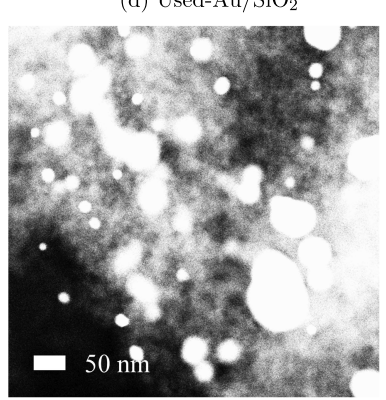

Figure 3. HAADF-STEM images of the $\mathrm{Au} / \mathrm{TiO}_{2}(\mathrm{a}, \mathrm{b})$ and $\mathrm{Au} / \mathrm{SiO}_{2}$ catalyst (c, d), before (left) and after reaction (right). Gold appears brighter than the supports because of the larger atomic number of gold compared to silicon and titanium. Additional images of $\mathrm{Au} / \mathrm{TiO}_{2}$ are available in the Supporting Information. dispersive X-ray spectroscopy (EDX). The fresh benchmark catalyst, $\mathrm{Au} / \mathrm{TiO}_{2}$ (Figure 3a), exhibits small rounded gold NPs with a size below $5 \mathrm{~nm}$. After the catalytic testing, the used $\mathrm{Au} / \mathrm{TiO}_{2}$ (Figure 3b) shows a slight increase in the size of gold NPs; most NPs remain below $5 \mathrm{~nm}$. The fresh $\mathrm{Au} / \mathrm{SiO}_{2}$ catalyst (Figure 3c) has on majority very large gold NPs, larger than $50 \mathrm{~nm}$, which differ from the spherical shape, typical for NPs. Some agglomerates, formed from the large particles, and a few small NPs below $10 \mathrm{~nm}$, are also visible. Overall, $\mathrm{Au} /$ $\mathrm{SiO}_{2}$ contains a range of sizes, from a few nanometer NPs to large agglomerates. The $\mathrm{Au} / \mathrm{SiO}_{2}$ catalyst does not exhibit any visible changes after catalytic testing. Large NPs and agglomerates are still present, while the few NPs below 10 $\mathrm{nm}$ appear resistant to sintering.

Figure 4 shows electron microscopy images of silica before and after impregnation with titanium. The fumed silica (Figure 4a), was amorphous with small NPs below $10 \mathrm{~nm}$. The support $\mathrm{Ti} @ \mathrm{SiO}_{2}$ (Figure 4b), which is silica impregnated with titanium treated at $300 \mathrm{~K}$ in vacuum, does not exhibit any distinguishable areas enriched in titanium. Figure $4 \mathrm{c}$ shows the EDX spectra from two unique positions of Figure $4 \mathrm{~b}$. We observe two large peaks at about 0.5 and $1.8 \mathrm{keV}$, which correspond to oxygen and silicon, respectively. The most intense peak of titanium is at about $4.6 \mathrm{keV}$. Comparing the intensity of the latter with that of silica, we get a ratio of about 0.05 in both positions. The support calcined at $473 \mathrm{~K}$ exhibited similar EDX spectra (Supporting Information). The EDX spectra show a homogeneous distribution of titanium over silica, which explains the absence of visible crystalline titania structures with microscopy.

Figure 5 shows the $\mathrm{Ti} @ \mathrm{SiO}_{2}$-supported gold catalyst before (left) and after catalytic testing (right). Gold deposited on the $\mathrm{Ti} @ \mathrm{SiO}_{2}$ support treated at $300 \mathrm{~K}$ in vacuum, $\mathrm{Au} / \mathrm{Ti} @ \mathrm{SiO}_{2}$ (Figure 5a), exhibits small gold NPs similarly as the benchmark $\mathrm{Au} / \mathrm{TiO}_{2}$ (Figure 3a). The NPs have a rounded shape and depict an almost uniform size, below $10 \mathrm{~nm}$, and a uniform distribution on the support. We can distinguish gold as a separate phase, but the titanium remains structurally indistinguishable from the silica support, the same as before gold deposition. There is no evidence of significant changes to the used catalyst, induced by the catalytic testing (Figure $5 b$ ). However, when the support undergoes thermal treatment before gold deposition, i.e., calcination at 473 and $1173 \mathrm{~K}$ (Figures 5c,e), the NPs clustered into large agglomerates. These are of irregular shape and larger than $20 \mathrm{~nm}$. The 
(a) $\mathrm{SiO}_{2}$

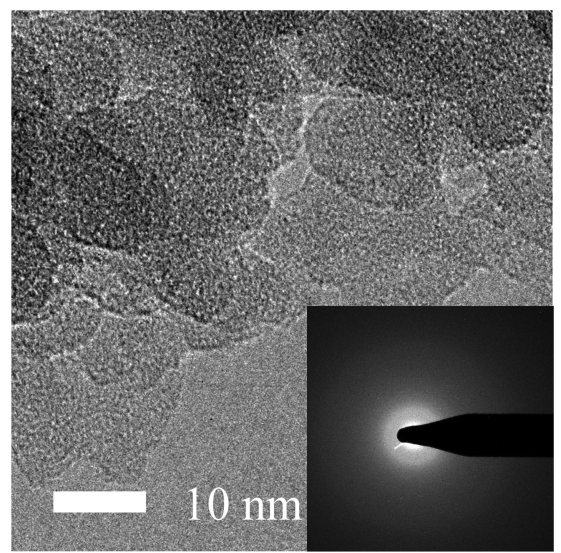

(b) $\mathrm{Ti} @ \mathrm{SiO}_{2}$

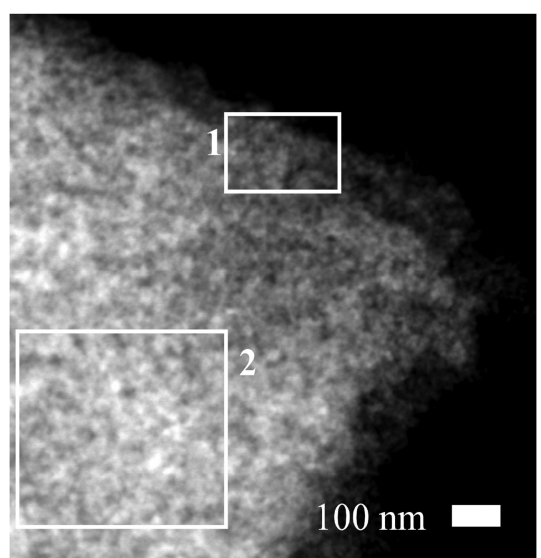

(c) $\mathrm{EDX}$ of $\mathrm{Ti} @ \mathrm{SiO}_{2}$
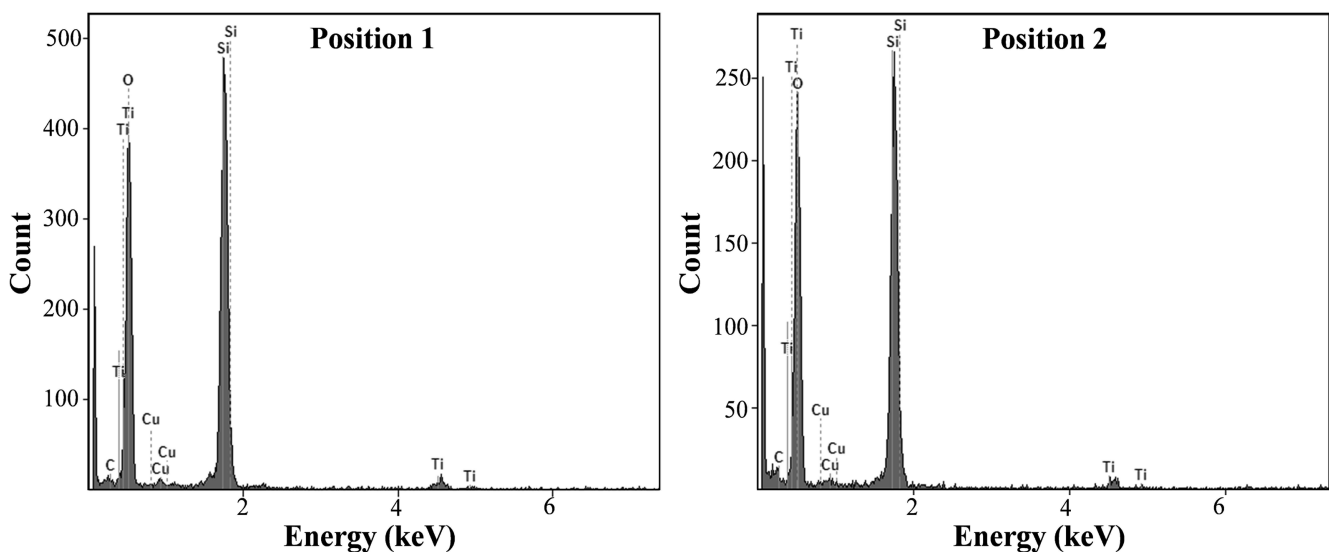

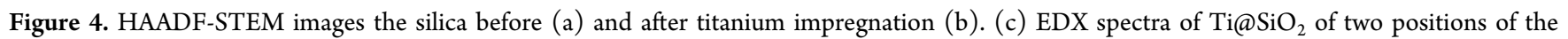
sample, as shown in image (b).

individual NPs, however, are round-shaped and smaller than $10 \mathrm{~nm}$, similar to the $\mathrm{Au} / \mathrm{Ti} @ \mathrm{SiO}_{2}$ catalysts. The number of observable agglomerates increases with the temperature of the treatment.

We determined the gold particle size distributions from the electron micrographs. All distributions were fitted with a lognormal function, typical for NPs; the distributions are available in the Supporting Information. Table 2 summarizes the parameters of the distribution. The mode of the particle size distribution follows the trend from smaller to larger NPs in the order $\mathrm{Au} / \mathrm{TiO}_{2}<\mathrm{Au} / \mathrm{Ti} @ \mathrm{SiO}_{2}<\mathrm{Au} / \mathrm{SiO}_{2}$. The fresh $\mathrm{Au} /$ $\mathrm{TiO}_{2}$ exhibits a narrow distribution with only a $0.9 \mathrm{~nm}^{2}$ variance. We observed NPs below $2 \mathrm{~nm}$ and only a few larger than $7 \mathrm{~nm}$. The log-normal fit of 370 particles gives a mode and mean particle size of 2.2 and $2.6 \mathrm{~nm}$, respectively. Repetition of microscopy of the sample after about 6 months in storage gave a mode and mean particle size of 4.1 and 4.9 $\mathrm{nm}$, respectively (Supporting Information). Small gold NPs sinter during storage and handling under light. ${ }^{10}$ Hence, we expect the catalyst during testing to have slightly larger NPs than the fresh $\mathrm{Au} / \mathrm{TiO}_{2}$, which however cannot exceed a mean particle size of $4.9 \mathrm{~nm}$. Au/ $\mathrm{Ti} @ \mathrm{SiO}_{2}$ contains NPs from 2.5 to $23 \mathrm{~nm}$, which results in a broader distribution than $\mathrm{Au} / \mathrm{TiO}_{2}$; the variance here is $10.9 \mathrm{~nm}^{2}$. The fit of 170 particles gives a mode and mean particle size of 6.3 and $8.0 \mathrm{~nm}$, respectively. The particle size is larger than the gold crystal size from fitting the XRD patterns (Figure 2), which was about $5 \mathrm{~nm}$. The differences between the size from XRD and microscopy are because of the difference of the two techniques, as XRD provides information only of the crystalline gold phase. Au/ $\mathrm{SiO}_{2}$ shows a very broad distribution exceeding $25 \mathrm{~nm}$. The particle size ranges from $5 \mathrm{~nm}$ up to more than $150 \mathrm{~nm}$ (Supporting Information), giving a large variance. The mode and mean particle size are 15 and $35 \mathrm{~nm}$, respectively. The catalyst comprising the thermally treated supports, Au/Ti@ $\mathrm{SiO}_{2}-200$ and $\mathrm{Au} / \mathrm{Ti} @ \mathrm{SiO}_{2}-900$, show very similar distributions, exhibiting NPs from 2 up to above $50 \mathrm{~nm}$, and with agglomerates not being accounted for by this measure. Au/ $\mathrm{Ti} @ \mathrm{SiO}_{2}-200$ has a mode and mean particle size of 4.3 and 9.8 nm, while Au/Ti@SiO $2-900$ has 4.7 and 8.4 nm, respectively. The distributions of the latter are much broader than the untreated $\mathrm{Au} / \mathrm{Ti} @ \mathrm{SiO}_{2}$; the variances are 68 and $34 \mathrm{~nm}_{2}$ for $\mathrm{Au} / \mathrm{Ti} @ \mathrm{SiO}_{2}-200$ and $\mathrm{Au} / \mathrm{Ti} @ \mathrm{SiO}_{2}-900$, respectively.

After catalytic testing at about $460 \mathrm{~K}$, most catalysts exhibit an increase of the gold particle size. We observed the smallest changes in the $\mathrm{Au} / \mathrm{Ti} @ \mathrm{SiO}_{2}$ catalyst: The mode increased by $0.3 \mathrm{~nm}$, and the mean particle size slightly decreased by 0.5 $\mathrm{nm}$, within the calculation error, suggesting a very similar particle size. The distribution of $\mathrm{Au} / \mathrm{TiO}_{2}$ after catalytic testing has shifted to larger particle size. The mode and mean particle sizes increased by 1.5 and $1.8 \mathrm{~nm}$, which is an increase of almost two times compared to the fresh samples. The thermally treated supported catalysts show only a slight increase of the gold particle size after catalytic testing. The 
(a) $\mathrm{Au} / \mathrm{Ti} @ \mathrm{SiO}_{2}$-fresh

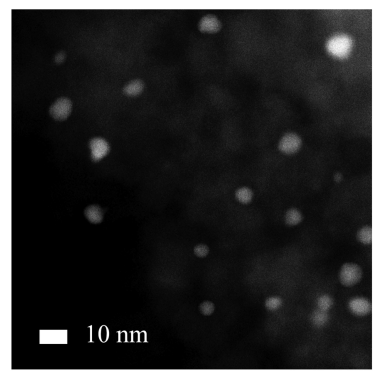

(c) $\mathrm{Au} / \mathrm{Ti} @ \mathrm{SiO}_{2}-200$-fresh

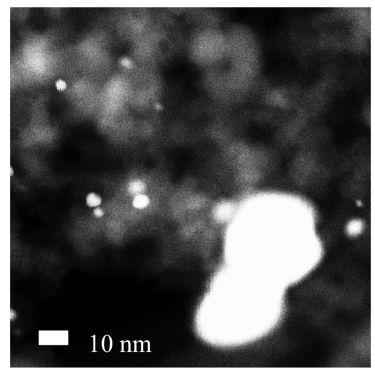

(e) $\mathrm{Au} / \mathrm{Ti} @ \mathrm{SiO}_{2}-900$-fresh

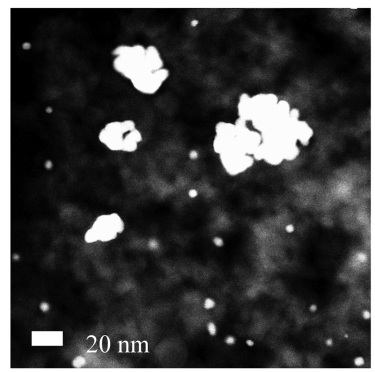

(b) $\mathrm{Au} / \mathrm{Ti} @ \mathrm{SiO}_{2}$-used

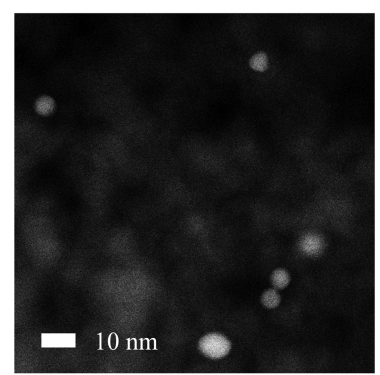

(d) $\mathrm{Au} / \mathrm{Ti} @ \mathrm{SiO}_{2}$-200-used

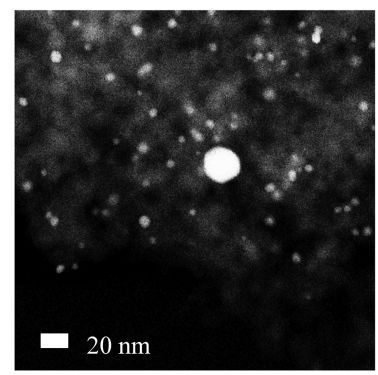

(f) $\mathrm{Au} / \mathrm{Ti} @ \mathrm{SiO}_{2}-900-$ used

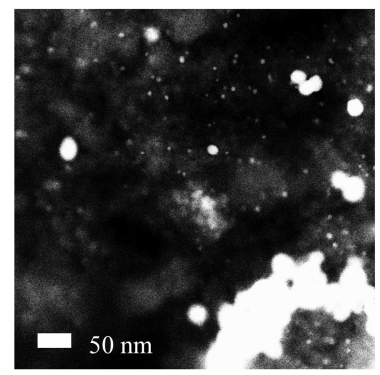

Figure 5. HAADF-STEM images of the Au/Ti@SiO 2 -based catalysts Au/Ti@SiO 2 (a, b), Au/Ti@SiO,-200 (c, d), and Au/Ti@SiO -900 (e, f), before (left) and after reaction (right). Gold appears brighter than the supports because of the larger atomic number of gold compared to silicon and titanium. Additional images are available in the Supporting Information.

Table 2. Summarized Values from the Gold Particle Lognormal Distributions ${ }^{a}$

\begin{tabular}{|c|c|c|c|c|c|c|}
\hline catalyst & $\mathrm{N}$ & $\mu$ & $\sigma$ & $\begin{array}{l}\text { mean } \\
(\mathrm{nm})\end{array}$ & $\underset{(\mathrm{nm})}{\operatorname{median}}$ & $\begin{array}{l}\text { mode } \\
(\mathrm{nm})\end{array}$ \\
\hline $\mathrm{Au} / \mathrm{SiO}_{2}$ & 141 & 3.27 & 0.75 & 34.6 & 26.2 & 15.0 \\
\hline $\mathrm{Au} / \mathrm{TiO}_{2}$ & 370 & 0.90 & 0.30 & 2.6 & 2.5 & 2.2 \\
\hline $\mathrm{Au} / \mathrm{Ti} @ \mathrm{SiO}_{2}$ & 170 & 2.00 & 0.39 & 8.0 & 7.4 & 6.3 \\
\hline $\mathrm{Au} / \mathrm{Ti} @ \mathrm{SiO}_{2}-200$ & 200 & 2.01 & 0.74 & 9.8 & 7.4 & 4.3 \\
\hline Au/Ti@SiO $2-900$ & 154 & 1.93 & 0.63 & 8.4 & 6.9 & 4.7 \\
\hline $\mathrm{Au} / \mathrm{SiO}_{2}$-used & 152 & 3.27 & 0.54 & 30.5 & 26.4 & 19.7 \\
\hline $\mathrm{Au} / \mathrm{TiO}_{2}$-used & 153 & 1.43 & 0.33 & 4.4 & 4.2 & 3.7 \\
\hline $\begin{array}{l}\mathrm{Au} / \mathrm{Ti} @ \mathrm{SiO}_{2^{-}} \\
\text {used }\end{array}$ & 132 & 1.97 & 0.29 & 7.5 & 7.2 & 6.6 \\
\hline $\begin{array}{c}\mathrm{Au} / \mathrm{Ti} @ \mathrm{SiO}_{2^{-}} \\
\text {200-used }\end{array}$ & 274 & 2.03 & 0.65 & 9.4 & 7.6 & 5.0 \\
\hline $\begin{array}{c}\mathrm{Au} / \mathrm{Ti} @ \mathrm{SiO}_{2-} \\
\text { 200-used }\end{array}$ & 228 & 2.37 & 0.77 & 14.4 & 10.7 & 5.9 \\
\hline
\end{tabular}

modal values of $\mathrm{Au} / \mathrm{Ti} @ \mathrm{SiO}_{2}-200$ and $\mathrm{Au} / \mathrm{Ti} @ \mathrm{SiO}_{2}-900$ increase by 0.7 and $1.2 \mathrm{~nm}$, respectively. Overall, the silica-

based supported catalysts appear most resistant to gold sintering compared to pure titania. As the catalysts exhibited relatively stable performance before and after exposure to high temperature (Supporting Information), we expect that the sintering occurred during the initial heating and contact with reactants before reaching a steady state.

Figure 6 shows the EDX spectra of the fresh $\mathrm{Au} / \mathrm{Ti} @ \mathrm{SiO}_{2}-$ 900, the catalyst with the largest agglomerate presence, on various locations of the sample. Positions 1, 5, and 6 are over small and large gold NPs where the EDX spectra exhibit gold presence. The gold peak intensity is small in the case of small NPs, at positions 1 and 6, but very profound at position 5, over the large gold particle. The gold peak is also present in the spectrum of position 3, which is in between the gold agglomerate that contributes to the spectrum. Positions 2 and 4 do not show peaks related to gold. All positions, independent of gold presence, exhibit silicon and titanium peaks. The most intense titanium peak appears at positions 3 and 5, near the gold aggregate and across the footprint of a large gold particle, respectively. The smallest intensity of titanium is at position 2, where gold is not present.

Figure 7 visualizes the EDX intensities of gold, titanium, and silica over the Au/Ti@SiO -900 after catalytic testing. The analyzed area contains both small, below $10 \mathrm{~nm}$, and large NPs, above $20 \mathrm{~nm}$. Silicon (red) appears everywhere in the sample. Titanium (blue) is present sporadically and distributed rather homogeneously, except in the area that forms a diagonal line connecting the gold NP, on the top right corner, where more titanium is present. The titanium-rich area is dense and larger than $100 \mathrm{~nm}$. The areas, where titanium is sparse, correspond to the absence of large gold NPs. The location of large NP therefore coincides with the presence of an excess of titanium. Hence, a large loading of titanium at a specific location results from the calcination of the support.

Figure 8a presents the Ti K edge XANES of $\mathrm{Au} / \mathrm{Ti} @ \mathrm{SiO}_{2}$ and of titanium foil and rutile titanium(IV) oxide. The spectrum of titanium foil has a very different pre-edge structure, with only one intense feature, at a lower energy, $\sim 4.967 \mathrm{keV}$. The spectrum of $\mathrm{Au} / \mathrm{Ti} @ \mathrm{SiO}_{2}$ displays three preedge peaks (features A1 to A3). These features are characteristics of titanium(IV); they come from the electron transitions from $1 \mathrm{~s}$ to $3 \mathrm{~d}$ orbitals and are like those observed for both rutile and anatase polymorphs of titania. ${ }^{30}$ In the spectrum of crystalline titania, those features have a low intensity because in an octahedral six-coordinated symmetry, the transitions from the $1 \mathrm{~s}$ to the empty $\mathrm{d}$ orbitals of the final state are forbidden. ${ }^{31,32}$ However, the near-edge features of the $\mathrm{Au} /$ $\mathrm{Ti} @ \mathrm{SiO}_{2}$ spectrum (features $\mathrm{B}$ and $\mathrm{C}$ ) differ from these in the spectrum of bulk titania. In the spectrum of $\mathrm{Au} / \mathrm{Ti} @ \mathrm{SiO}_{2}$, the edge position is at $4.984 \mathrm{keV}$, as expected for titanium(IV), but the shoulder (feature B), a characteristic of both rutile and anatase, is not present. Two features, $\mathrm{C1}^{\prime}$ and $\mathrm{C}^{\prime}$, replaced the three features $\mathrm{C} 1-\mathrm{C} 3$ of the rutile; $\mathrm{C}^{\prime}{ }^{\prime}$ and $\mathrm{C}^{\prime}{ }^{\prime}$ are of similar intensity. The characteristic features of the Ti K edge XANES suggest neither rutile nor anatase titania. ${ }^{30,33}$ Instead, the spectrum resembles those derived from amorphous titania and mono-dispersed titanium species in titanium silicalites. ${ }^{33-36}$ The latter explains the absence of crystalline titania peaks in the XRD patterns (Figure 2).

The pre-edge feature A2 were further investigated since its position and height are characteristic indicative of the coordination and symmetry of titanium. ${ }^{37-39}$ The pre-edge features of the spectra of $\mathrm{Au} / \mathrm{Ti} @ \mathrm{SiO}_{2}$ and titania rutile were 
(a) EDX spectra

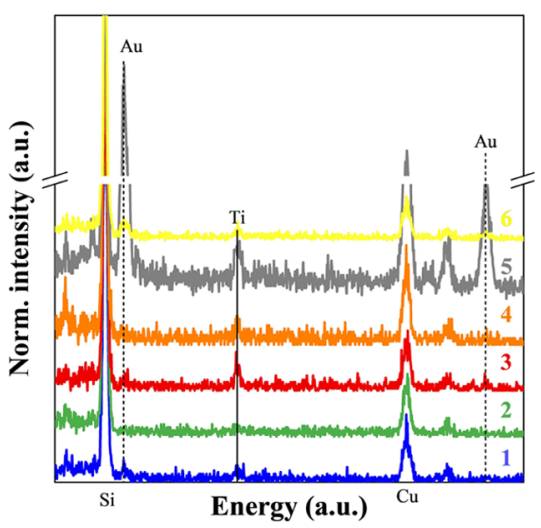

(b) Sampling area of each spectrum

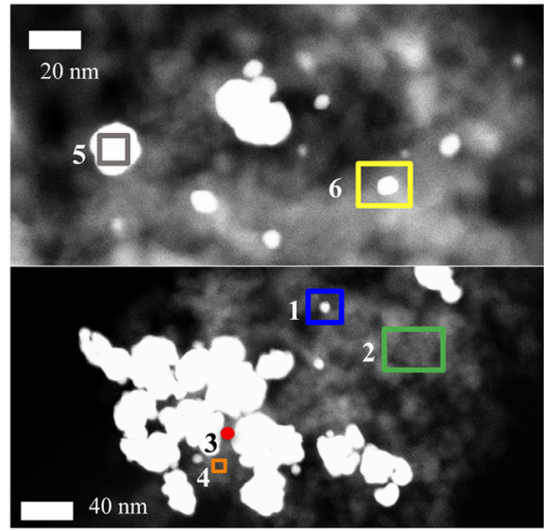

Figure 6. EDX spectra (a) of unique locations on the Au-TISi-900 (b): On a gold NP (position 1), away from gold (position 2) and near large gold aggregates (positions 3 and 4 ). The peaks are $\mathrm{Si}, \mathrm{Au}, \mathrm{Ti}$, and $\mathrm{Cu}$ (sample holder).

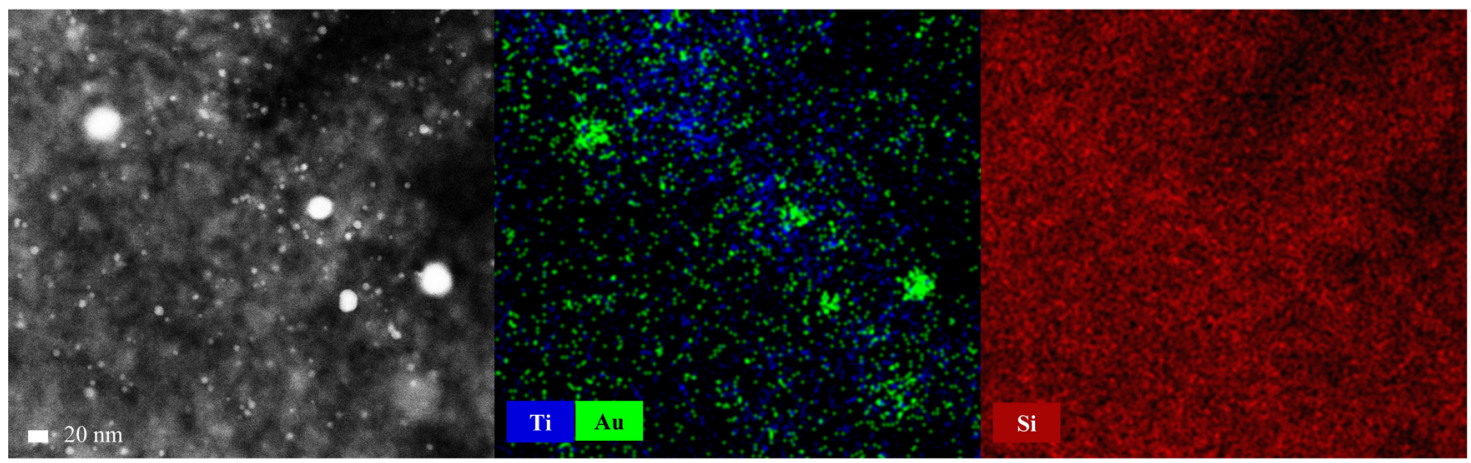

Figure 7. EDX mapping of the used $\mathrm{Au} / \mathrm{Ti} @ \mathrm{SiO}_{2}-900$.

(a) XANES spectra

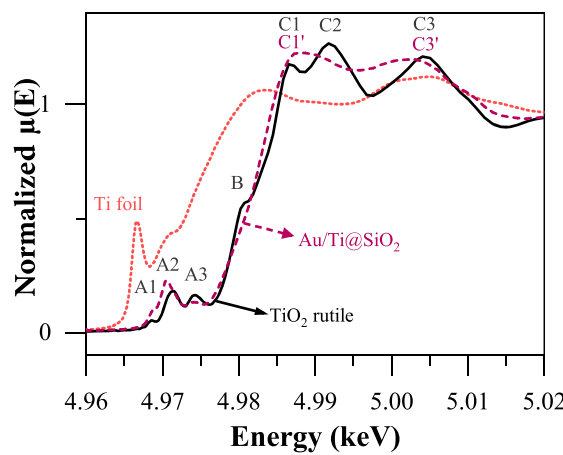

(b) Gaussian fit of A2

\begin{tabular}{lcc}
\hline Spectrum & $\begin{array}{c}\text { Position } \\
\text { (keV) }\end{array}$ & $\begin{array}{c}\text { Normalized } \\
\text { height }\end{array}$ \\
\hline Rutile & 4.9712 & 0.16 \\
$\mathrm{Au} / \mathrm{Ti} @ \mathrm{SiO}_{2}$ & 4.9706 & 0.18 \\
error & \pm 0.0005 & \pm 0.01 \\
\hline
\end{tabular}

Figure 8. (a) Ti K edge XANES of the fresh $\mathrm{Au} / \mathrm{Ti} @ \mathrm{SiO}_{2}$ (broken lines), and of the references $\mathrm{Ti}^{0}$ ( $\mathrm{Ti}$ foil, dotted line) and $\mathrm{Ti}^{4+}\left(\mathrm{TiO}_{2}\right.$ rutile, straight line). We measured the sample in fluorescence and the reference samples in transmission mode. (b) Peak position and intensity of A2 preedge feature defined by Gaussian fitting. The fittings are available in the Supporting Information.

fitted with a Gaussian function (Supporting Information). The table in Figure $8 \mathrm{~b}$ presents the peak position and height of feature $\mathrm{A} 2$. The position of $\mathrm{A} 2$ in the spectrum of rutile from our data is at $4.971 \mathrm{keV}$, similar to the one reported for rutile, at $4.972 \mathrm{keV}$, and to other six-coordinated systems, which vary from 4.971 to $4.972 \mathrm{keV}^{39}$ The height of the peak A2 of our rutile sample is 0.16 , somewhat lower than the typical rutile, which is 0.22 . The position of peak A2 in the spectrum of the $\mathrm{Au} / \mathrm{Ti} @ \mathrm{SiO}_{2}$ sample is at $4.971 \mathrm{keV}$, which places it at the region corresponding to five-coordinated titanium; in such systems, the position of $\mathrm{A} 2$ is between 4.971 and $4.971 \mathrm{keV}{ }^{39}$ The normalized height of the A2 of Au/Ti@SiO 2 is, however,
0.18 , which is characteristic of six-coordinated; even considering the error from the subtraction of the baseline, the intensity of this feature is still significantly less than the of five-coordinated titanium, which is between 0.43 and 0.73 . The position and height of the $\mathrm{A} 2$ of $\mathrm{Au} / \mathrm{Ti} @ \mathrm{SiO}_{2}$ suggest that there is a mixture of titanium coordination, varying from sixfold to five-fold. ${ }^{39}$ The titanium coordination of our system appears not six-coordinated, as typically in rutile and anatase.

We evaluated the EXAFS region of the Ti $\mathrm{K}$ edge spectrum of the Au/Ti@SiO ${ }_{2}$ catalyst. We fitted the spectrum with distinct fits, considering different scatterers for the first and second shell of neighboring atoms. Figure 9 visualizes each 
(a) Ti K edge EXAFS in k-space

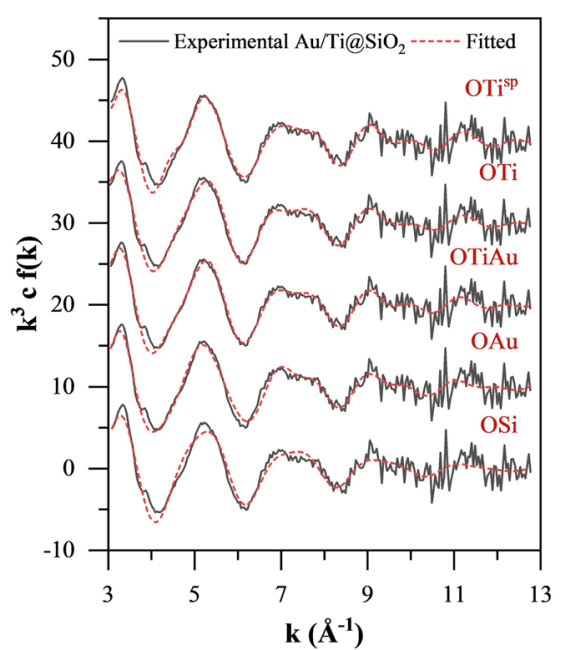

(b) Ti K edge EXAFS in R-space

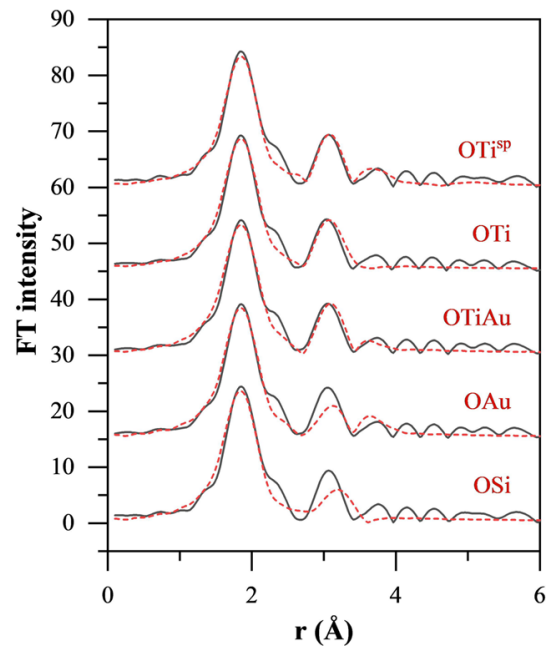

Figure 9. Ti K edge EXAFS in the $k$-space (a) and $R$-space (b) of the fresh Au/Ti@SiO 2 ex situ (straight line) compared with fitted (broken line) considering different scatterers. Parameters: $K_{\min }=3, K_{\max }=13, \mathrm{AFAC}=0.9$

distinct fit (dotted line) with the experimental $\mathrm{Ti} \mathrm{K}$ edge spectrum of the $\mathrm{Au} / \mathrm{Ti} @ \mathrm{SiO}_{2}$ catalyst All fits reproduce the first feature of the data at about $1.8 \AA$, the shoulder of this feature, which does not appear in the fit; we found it to be a function of the apodization function used to generate the Fourier transfer and therefore an artifact (Supporting Information). The second pronounced feature in the data at about $3 \AA$ is best reproduced by the first three fits, which place titanium in the second shell. When we considered titanium absent and silicon or gold present in the second scattering shell, as in the last two fits, the fit cannot reproduce well the features of the second shell at all. That shows that the titanium in the $\mathrm{Au} / \mathrm{Ti} @ \mathrm{SiO}_{2}$ is not present as monomers on the silica surface, or in the silica structure. The third, low intensity feature at about $3.7 \AA$ could be fitted in two ways: First, as the result of multiple scattering of the titanium was constrained to occupy a square planar configuration and second, as the result of a hypothetical titanium-gold interaction in in the second shell. The above, overall, suggest that titanium is highly dispersed, possibly in dimers or trimers, on the surface of the silica.

Table 3 presents the EXFAS fitted parameters as generated by Fourier transform. The data suggests 4.7 to 4.9 oxygen atoms in the first shell, indicating five-coordinated titanium at about $1.9 \AA$ distance.

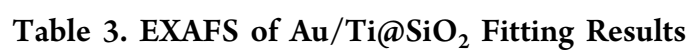

\begin{tabular}{cccccccc}
\multicolumn{7}{c}{ parameters: $K_{\min }=3, K_{\max }=14, \mathrm{AFAC}=0.8$} \\
\hline fit & scatterer & $N$ & $R(\AA)$ & $\mathrm{DW}$ & $\mathrm{EF}$ & $R(\%)$ & chi \\
AuSiTi & $\mathrm{O}$ & 4.7 & 1.89 & 0.020 & 4.7 & 34.5 & 4.7 \\
& $\mathrm{Au}$ & 1.8 & 3.06 & 0.01 & & & \\
\multirow{2}{*}{$\mathrm{OTi}$} & $\mathrm{O}$ & 4.8 & 1.90 & 0.021 & 4.1 & 32.1 & 4.27 \\
& $\mathrm{Ti}$ & 1.6 & 3.06 & 0.016 & & & \\
\multirow{2}{*}{$\mathrm{AuTi}$} & $\mathrm{O}$ & 4.9 & 1.89 & 0.021 & 4.9 & 36.8 & 4.81 \\
& $\mathrm{Au}$ & 1.8 & 3.06 & 0.018 & & & \\
$\mathrm{SiTi}$ & $\mathrm{O}$ & 4.9 & 1.88 & 0.021 & 5.5 & 39.7 & 4.96 \\
& $\mathrm{Si}$ & 1.7 & 3.02 & 0.016 & & &
\end{tabular}

\section{DISCUSSION}

We have synthesized a titanium-silica material, Ti@SiO support for gold NPs and tested it in the ethanol oxidation. Gold NPs below $10 \mathrm{~nm}$ were successfully formed only in the presence of titanium. Pure silica as support resulted in very large particles and agglomerates, which rendered $\mathrm{Au} / \mathrm{SiO}_{2}$ inactive for ethanol oxidation (Figure 1). Hence, the chosen synthesis, an adaptation of the deposition precipitation with urea, which is the most efficient deposition precipitation variation for titania support, is not suitable for silica. ${ }^{22}$ Theoretical studies suggest that gold clusters bind with small adsorption energies on silica, which results in mobility and rapid sintering of the clusters at finite temperatures. ${ }^{21}$ For the formation of gold NPs, over less-interactive supports, such as silica, it is common to use gold colloids, which are then immobilized on the support. ${ }^{5,40,41}$

We thoroughly investigated the structures of the Au/Ti@ $\mathrm{SiO}_{2}$ catalyst and the $\mathrm{Ti} @ \mathrm{SiO}_{2}$ supports to determine the structure of titanium. Ti $\mathrm{K}$ edge XANES shows that the titanium in the Au/Ti@SiO ${ }_{2}$ sample (Figure 8a) is present as titanium(IV). However, the local structure of titanium is not typical to that of crystalline rutile or anatase. The pre-edge feature (Figure 8a), a characteristic of the titanium coordination, has an intensity that corresponds to mixedcoordinated titanium, either distorted six-coordinated titanium or a mixture of titanium species of both five- and sixcoordination in the sample. The EXAFS analysis (Table 3), pinpoint toward the five-coordinated titanium. Similarly, distortion from the octahedral symmetry was observed in mono-dispersed titanium on silica, where the symmetry depends on the surface species. ${ }^{34,35}$ Hence, determining with certainty the coordination in our systems is not a simple task because the intensity of the relevant features falls well-below the threshold expected from the bulk materials. That may be because of the non-extended nature of these species (molecular bonding rather than bands structure) and/or different degrees of distortion. Electron microscopy indicates that titanium in the support is evenly and highly dispersed on the surface (Figures 4 and 6). Overall, the most likely structure of the titanium species on the silica surface comprises homogeneously distributed titanium(IV) atoms, possibly 
oxidic in nature, which extend up to two shells; essentially, they are isolated oligomeric structures. For these strongly bound titanium atoms diffusion is curtailed as is , correspondingly, the formation of larger, crystalline structures.

These amorphous structures of the titanium(IV) are very stable to the conditions used to deposit the gold. However, we observed some structural changes after thermal treatment of the support at $1173 \mathrm{~K}$, where larger, EDX visible (Figure 7) but XRD silent (Figure 2), titanium clusters are observed. Such a treatment is well-above the temperature required for the irreversible transition of, for instance, anatase to rutile, the most thermodynamically stable titania form; bulk anatase starts transforming to rutile at about $873 \mathrm{~K}$ in air. ${ }^{42}$ Here, the changes in the titanium structures also influence the gold particle formation and mobility. EDX mapping showed areas rich in titanium, where we also observed sintering and agglomerates of small gold particles. Still, small NPs, below $10 \mathrm{~nm}$, are retained in all $\mathrm{Ti} @ \mathrm{SiO}_{2}$-supported catalysts, which renders them catalytically activity, in contrast to $\mathrm{Au} / \mathrm{SiO}_{2}$.

The Au/Ti@SiO -based catalysts showed conversions similar to the benchmark $\mathrm{Au} / \mathrm{TiO}_{2}$ but with improved acetic acid yield (Figure 1). The best catalyst was the Au/Ti@SiO 200 , which showed up to a $10 \%$ increase in acetic acid yield compared to $\mathrm{Au} / \mathrm{TiO}_{2}$. Such an increase is attributed mainly to the properties of the titanium-silica support. The main parameters in catalysis by gold are the gold particle size, dispersion and loading, and the support. ${ }^{11}$ The gold particle size commonly accepted as active is well below $10 \mathrm{~nm}$. In our system, we observed that catalysts with particles close to $10 \mathrm{~nm}$ mean are highly active, in spite of the presence of gold agglomerates in TEM. This indicates that the catalytic properties of the $\mathrm{Au} / \mathrm{Ti} @ \mathrm{SiO}_{2}$-based catalysts may not be as sensitive to the gold particle size as has been typically observed for $\mathrm{Au} / \mathrm{TiO}_{2} \cdot{ }^{19}$ Other than the properties of the support and particle size, no other differences can explain the selectivity differences between $\mathrm{Au} / \mathrm{TiO}_{2}$ and the $\mathrm{Au} / \mathrm{Ti} @ \mathrm{SiO}_{2}$ catalysts. The small differences in gold loadings, up to maximum $0.2 \mathrm{wt}$ $\%$ are not significant enough to play a detrimental role in the catalyst activity. The detailed study of Dong et al. has shown less than $10 \%$ additional conversion when increasing the loading from 1 to $4 \mathrm{wt} \%$ and that catalysts with the same loading exhibit significant differences activity due to different gold particle sizes. ${ }^{9}$ Overall, the chemical properties of the $\mathrm{Au} /$ $\mathrm{Ti} @ \mathrm{SiO}_{2}$ support is the main driving force of improved selectivity.

At the same time, the catalytic activity does not exhibit any correlation with the presence of bulk titania. The titanium species in $\mathrm{Au} / \mathrm{Ti} @ \mathrm{SiO}_{2}$ catalysts locally should retain some of the properties of titania, which can explain their similarities with $\mathrm{Au} / \mathrm{TiO}_{2}$ in terms of catalytic activity. However, some properties of bulk titania, such as crystallinity, are not present in the titania of Au/Ti@SiO 2 . The high activity of the Au/Ti@ $\mathrm{SiO}_{2}$ catalysts suggests that those bulk properties of titania are, therefore, not essential to the reaction.

The reported Au/Ti@SiO ${ }_{2}$ catalysts offer a fresh alternative to the currently-best-performing titania-supported catalyst. Using silica as support has the advantage of high surface area; silica can reach up to an order of magnitude larger surface area than titania. The addition of low levels, below $5 \mathrm{wt} \%$, of titanium eliminates the limitations of pure silica-supported gold, over which gold particles can easily sinter making the synthesis method more complicated and increasing the potential for deactivation during reaction. Hence, the here- reported synthesis allows the formation of a catalyst with a larger surface area, which can further improve the acetic acid yield. Additionally, we show here that even a small loading of titanium favors the formation of small and stable gold particles that perform similar or even better than gold on titania.

\section{CONCLUSIONS}

The here-reported synthesis of gold supported on a Ti@SiO catalyst resulted in a homogeneously distributed and highly dispersed titanium(IV) structure on the surface of silica. This structure is very stable and remains dispersed even after gold preposition conditions. The presence of these titanium structures allowed for the formation of stable small gold particles. However, thermal treatment of the support at 1,173 $\mathrm{K}$ before gold deposition does induce mobility of the titanium, to yield large aggregates of particles, but still not to the degree where these become XRD visible.

Despite the presence of aggregates and larger particles, the $\mathrm{Ti} @ \mathrm{SiO}_{2}$-supported gold catalysts exhibited similar or improved yields of acetic acid compared to the state-of-theart $\mathrm{Au} / \mathrm{TiO}_{2}$. The high activity of these catalysts demonstrates that bulk, crystalline titania is necessary for the catalytic reaction. The best performing catalyst was gold supported on $\mathrm{Ti} @ \mathrm{SiO}_{2}$ calcined at $447 \mathrm{~K}$ with a maximum acetic acid yield of about $26 \%$ at $453 \mathrm{~K}$; compared to $\mathrm{Au} / \mathrm{TiO}_{2}$, the acetic acid yield improved by a factor of about 1.8 at each tested condition. The Ti@SiO 2 -supported gold catalysts therefore show considerable potential for high catalytic performance, while the use of silica can improve the physical properties of the catalyst, such as surface area and mechanical stability.

As $\mathrm{Au} / \mathrm{Ti} @ \mathrm{SiO}_{2}$ contains only 5 wt \% titania homogeneously distributed on the silica surface and exhibits similar catalytic activity as $\mathrm{Au} / \mathrm{TiO}_{2}$, it can be used as a model catalyst for investigating the role of titania-gold interface on the adsorption of reactants and products. This catalyst formulation enables for the first time the use of bulk operando characterization techniques, such X-ray spectroscopy, to study the structural changes of titanium atoms around the interface of gold. Accordingly, we are currently conducting a mechanistic study, aiming to identify the roles of the support and the adsorption sites of reactants and products.

\section{ASSOCIATED CONTENT}

\section{SI Supporting Information}

The Supporting Information is available free of charge at https://pubs.acs.org/doi/10.1021/acs.iecr.0c02939.

Additional catalytic testing data of Au/Ti@SiO 2 and of other supported gold catalysts and detailed characterization data for all reported $\mathrm{Au} / \mathrm{Ti} @ \mathrm{SiO}_{2}$ catalysts (PDF)

\section{AUTHOR INFORMATION}

\section{Corresponding Author}

Jeroen A. van Bokhoven - Institute for Chemical and Bioengineering, Department of Chemistry and Applied Biosciences, ETH Zürich, 8093 Zurich, Switzerland; Laboratory for Catalysis and Sustainable Chemistry, Paul Scherrer Institute, 5232 Villigen, Switzerland; (1) orcid.org/ 0000-0002-4166-2284; Email: jeroen.vanbokhoven@ chem.ethz.ch 


\section{Authors}

Sotiria Mostrou - Institute for Chemical and Bioengineering, Department of Chemistry and Applied Biosciences, ETH Zürich, 8093 Zurich, Switzerland; 다이.org/0000-00030887-9163

Mark A. Newton - Institute for Chemical and Bioengineering, Department of Chemistry and Applied Biosciences, ETH Zürich, 8093 Zurich, Switzerland; ㅇo orcid.org/0000-00026389-2144

Andreas Tarcevski - Institute for Chemical and Bioengineering, Department of Chemistry and Applied Biosciences, ETH Zürich, 8093 Zurich, Switzerland

Andreas Nagl - Institute of Material Chemistry, Division Physical Chemistry, TU Wien, 1060 Vienna, Austria

Karin Föttinger - Institute of Material Chemistry, Division Physical Chemistry, TU Wien, 1060 Vienna, Austria; (1) orcid.org/0000-0002-2193-0755

Complete contact information is available at:

https://pubs.acs.org/10.1021/acs.iecr.0c02939

\section{Notes}

The authors declare no competing financial interest.

\section{ACKNOWLEDGMENTS}

The authors thank Dr. Frank Krumeich and the Electron Microscopy Centre of ETH Zurich for the microscopy analysis. We are grateful to Dr. Shusaku Hayama and the I10 beam-line at Diamond light source for the support with the X-ray absorption experiments. We are thankful to Mr. Joel Jenni, Mr. Fredy Mettler, and the mechanical workshop of chemical engineering in ETH for their critical input and technical support on the experimental setup. This research was funded by the Swiss National Foundation (SNF 200021E-158188) and by the Austrian Science Fund (FWF I2158-N28). M.A.N. thanks Shell Global solutions for the funding of his position.

\section{REFERENCES}

(1) Rass-Hansen, J.; Falsig, H.; Jørgensen, B.; Christensen, C. H. Bioethanol: Fuel or feedstock? J. Chem. Technol. Biotechnol. 2007, 82, 329-333.

(2) Gallo, J. M. R.; Bueno, J. M. C.; Schuchardt, U. Catalytic transformations of ethanol for biorefineries. J. Braz. Chem. Soc. 2014, 25, 2229-2243.

(3) Christensen, C. H.; Jørgensen, B.; Rass-Hansen, J.; Egeblad, K.; Madsen, R.; Klitgaard, S. K.; Hansen, S. M.; Hansen, M. R.; Andersen, H. C.; Riisager, A. Formation of acetic acid by aqueous-phase oxidation of ethanol with air in the presence of a heterogeneous gold catalyst. Angew. Chem., Int. Ed. 2006, 45, 4648-4651.

(4) Jørgensen, B.; hristiansen, S. E.; Thomsen, M. L.; Christensen, C. $\mathrm{H}$. Aerobic oxidation of aqueous ethanol using heterogeneous gold catalysts: Efficient routes to acetic acid and ethyl acetate. J. Catal. 2007, 251, 332-337.

(5) Sun, K.-Q.; Luo, S.-W.; Xu, N.; Xu, B.-Q. Gold nano-size effect in $\mathrm{Au} / \mathrm{SiO}_{2}$ for selective ethanol oxidation in aqueous solution. Catal. Lett. 2008, 124, 238-242.

(6) Heeskens, D.; Aghaei, P.; Kaluza, S.; Strunk, J.; Muhler, M. Selective oxidation of ethanol in the liquid phase over $\mathrm{Au} / \mathrm{TiO}_{2}$. Phys. Status Solidi 2013, 250, 1107-1118.

(7) Aghaei, P.; Berger, R. J. Reaction kinetics investigation of the selective oxidation of aqueous ethanol solutions with air over a $\mathrm{Au}$ / $\mathrm{TiO}_{2}$ catalyst. Appl. Catal., B 2013, 132-133, 195-203.

(8) Zope, B. N.; Hibbitts, D. D.; Neurock, M.; Davis, R. J. Reactivity of the Gold/Water Interface During Selective Oxidation Catalysis. Science 2010, 330, 74-78.
(9) Dong, W.; Reichenberger, S.; Chu, S.; Weide, P.; Ruland, H.; Barcikowski, S.; Wagener, P.; Muhler, M. The effect of the Au loading on the liquid-phase aerobic oxidation of ethanol over $\mathrm{Au} / \mathrm{TiO}_{2}$ catalysts prepared by pulsed laser ablation. J. Catal. 2015, 330, 497-506.

(10) Zanella, R.; Louis, C. Influence of the conditions of thermal treatments and of storage on the size of the gold particles in $\mathrm{Au} / \mathrm{TiO}_{2}$ samples. Catal. Today 2005, 107-108, 768-777.

(11) Haruta, M. Size- and support-dependency in the catalysis of gold. Catal. Today 1997, 36, 153-166.

(12) Mavrikakis, M.; Stoltze, P.; Nørskov, J. K. Making gold less noble. Catal. Lett. 2000, 64, 101-106.

(13) Haruta, M. When gold is not noble: Catalysis by nanoparticles. Chem. Rec. 2003, 3, 75-87.

(14) Meng, Q.; Shen, Y.; Xu, J.; Gong, J. Mechanistic Insights into Selective Oxidation of Ethanol on $\mathrm{Au}(111)$ : A DFT Study. Chin. J. Catal. 2012, 33, 407-415.

(15) Gu, Q.; Sautet, P.; Michel, C. Unraveling the Role of Base and Catalyst Polarization in Alcohol Oxidation on $\mathrm{Au}$ and $\mathrm{Pt}$ in Water. ACS Catal. 2018, 8, 11716-11721.

(16) Mostrou, S.; Nagl, A.; Ranocchiari, M.; Föttinger, K.; van Bokhoven, J. A. The catalytic and radical mechanism for ethanol oxidation to acetic acid. Chem. Commun. 2019, 55, 11833-11836.

(17) Haruta, M.; Tsubota, S.; Kobayashi, T.; Kageyama, H.; Genet, M. J.; Delmon, B. Low-Temperature Oxidation of $\mathrm{CO}$ over Gold Supported on TiO2, $\alpha$-Fe2O3, and Co3O4. J. Catal. 1993, 144, 175192.

(18) Campbell, C. T.; Sellers, J. R. V. Anchored metal nanoparticles: Effects of support and size on their energy, sintering resistance and reactivity. Faraday Discuss. 2013, 162, 9-30.

(19) Mostrou, S.; Sipőcz, T.; Nagl, A.; Fődi, B.; Darvas, F.; Föttinger, K.; Van Bokhoven, J. A. Catalytic oxidation of aqueous bioethanol: An efficient upgrade from batch to flow. React. Chem. Eng. 2018, 3, 781-789.

(20) Ayude, M. A.; Doumic, L. I.; Cassanello, M. C.; Nigam, K. D. P. Clean Catalytic Oxidation for Derivatization of Key Biobased Platform Chemicals: Ethanol, Glycerol, and Hydroxymethyl Furfural. Ind. Eng. Chem. Res. 2019, 58, 16077-16095.

(21) Schlexer, P.; Pacchioni, G. Anchoring Small Au Clusters on the Dehydroxylated and Hydroxylated $\mathrm{SiO}_{2} \alpha$-Quartz (001) Surface via Ti-Alloying. J. Phys. Chem. C 2017, 121, 14717-14724.

(22) Zanella, R.; Giorgio, S.; Henry, C. R.; Louis, C. Alternative Methods for the Preparation of Gold Nanoparticles Supported on $\mathrm{TiO}_{2}$. J. Phys. Chem. B 2002, 106, 7634-7642.

(23) Coelho, A. A. TOPAS and TOPAS-Academic: An optimization program integrating computer algebra and crystallographic objects written in C++. J. Appl. Crystallogr. 2018, 51, 210-218.

(24) Scherrer, P. Kolloidchem; Ein, L.; Zsigmondy, R., Ed.; Springer: Berlin, Heidelberg, 1912; pp. 387-409.

(25) Krumeich, F.; Müller, E.; Wepf, R. A.; Nesper, R. Characterization of Catalysts in an Aberration-Corrected Scanning Transmission Electron Microscope. J. Phys. Chem. C 2011, 115, 10801083.

(26) Ravel, B.; Newville, M. ATHENA, ARTEMIS, HEPHAESTUS: Data analysis for X-ray absorption spectroscopy using IFEFFIT. J. Synchrotron Radiat. 2005, 537-541.

(27) Binsted, N.; Strange, R. W.; Hasnain, S. S. Constrained and Restrained Refinement in EXAFS Data Analysis with Curved Wave Theory. Jpn. J. Appl. Phys. 1993, 32, 141-143.

(28) Stern, E. A.; Sayers, D. E.; Lytle, F. W. Extended x-rayabsorption fine-structure technique. III. Determination of physical parameters. Phys. Rev. B 1975, 11, 4836-4846.

(29) Hamdan, H.; Muhid, M. N. M.; Endud, S.; Listiorini, E.; Ramli, Z. 29Si MAS NMR, XRD and FESEM studies of rice husk silica for the synthesis of zeolites. J. Non-Cryst. Solids 1997, 211, 126-131.

(30) Yoshida, S.; Takenaka, S.; Tanaka, T.; Hirano, H.; Hayashi, H. Highly dispersed titanium oxide on silica: preparation, characterization by $X A F S$, and photocatalysis; In 11th Int. Congr. Catal. - 40th Anniv.; Elsevier Science: New York, NY (United States); 1996; pp. 871-880. 
(31) Babonneau, F.; Doeuff, S.; Leaustic, A.; Sanchez, C.; Cartier, C.; Verdaguer, M. XANES and EXAFS Study of Titanium Alkoxides. Inorg. Chem. 1988, 27, 3166-3172.

(32) Bordiga, S.; Boscherini, F.; Coluccia, S.; Genonic, F.; Lamberti, C.; Leofanti, G.; Marchese, L.; Petrini, G.; Vlaic, G.; Zecchina, A. XAFS study of Ti-silicalite: structure of framework Ti(IV) in presence and in absence of reactive molecules $\left(\mathrm{H}_{2} \mathrm{O}, \mathrm{NH}_{3}\right)$. Catal. Lett. 1994, 26, 195-208.

(33) Budarz, J.; Santomauro, F. G.; Rittmann-Frank, M. H.; Milne, C. J.; Huthwelker, T.; Grolimund, D.; Rittmann, J.; Kinschel, D.; Rossi, T.; Chergui, M. Time-resolved Element-selective Probing of Charge Carriers in Solar Materials. Chim. Int. J. Chem. 2017, 71, 768772 .

(34) Bordiga, S.; Coluccia, S.; Lamberti, C.; Marchese, L.; Zecchina, A.; Boscherini, F.; Buffa, F.; Genoni, F.; Leofanti, G. XAFS Study of Ti-Silicalite: Structure of Framework $\mathrm{Ti}(\mathrm{IV})$ in the Presence and Absence of Reactive Molecules $\left(\mathrm{H}_{2} \mathrm{O}, \mathrm{NH}_{3}\right)$ and Comparison with Ultraviolet-Visible and IR Results. J. Phys. Chem. 1994, 98, 41254132.

(35) Zecchina, A.; Bordiga, S.; Lamberti, C.; Ricchiardi, G.; Lamberti, C.; Ricchiardi, G.; Scarano, D.; Petrini, G.; Leofanti, G.; Mantegazza, M. Structural characterization of $\mathrm{Ti}$ centres in $\mathrm{Ti}$ silicalite and reaction mechanisms in cyclohexanone ammoximation. Catal. Today 1996, 32, 97-106.

(36) Bordiga, S.; Bonino, F.; Damin, A.; Lamberti, C. Reactivity of $\mathrm{Ti}(\mathrm{IV})$ species hosted in TS-1 towards $\mathrm{H}_{2} \mathrm{O} \quad 2-\mathrm{H}_{2} \mathrm{O}$ solutions investigated by ab initio cluster and periodic approaches combined with experimental XANES and EXAFS data: A review and new highlights. Phys. Chem. Chem. Phys. 2007, 9, 4854-4878.

(37) Farges, F.; Brown, G. E., Jr.; Navrotsky, A.; Gan, H.; Rehr, J. J. Coordination chemistry of $\mathrm{Ti}(\mathrm{IV})$ in silicate glasses and melts: II. Glasses at ambient temperature and pressure. Geochim. Cosmochim. Acta 1996, 60, 3039-3053.

(38) Farges, F.; Brown, G. E., Jr.; Rehr, J. J. Coordination chemistry of $\mathrm{Ti}(\mathrm{IV})$ in silicate glasses and melts: I. XAFS study of titanium coordination in oxide model compounds. Geochim. Cosmochim. Acta 1996, 60, 3023-3038.

(39) Farges, F.; Brown, G. E.; Rehr, J. J. Tik-edge XANES studies of $\mathrm{Ti}$ coordination and disorder in oxide compounds: Comparison between theory and experiment. Phys. Rev. B 1997, 56, 1809-1819.

(40) Porta, F.; Prati, L.; Rossi, M.; Coluccia, S.; Martra, G. Metal sols as a useful tool for heterogeneous gold catalyst preparation: Reinvestigation of a liquid phase oxidation. Catal. Today 2000, 61, 165-172.

(41) Beloqui Redondo, A.; Ranocchiari, M.; Van Bokhoven, J. A. Synthesis of sub-nanometer gold particles on modified silica. Dalton Trans. 2016, 45, 2983-2988.

(42) Hanaor, D. A. H.; Sorrell, C. C. Review of the anatase to rutile phase transformation. J. Mater. Sci. 2011, 46, 855-874. 